\title{
Paces narcotizadas. Diálogos del Caguán y La Habana en perspectiva comparada*
}

Narcotized peace. Negotiations of the Caguan and Havana

in comparative perspective

\section{ESTEBAN ARRATIA SANDOVAL**}

Universidad de Santiago de Chile, Chile

esteban.arratia@usach.cl

DIEGO JIMÉNEZ CABRERA

Universidad de Santiago de Chile, Chile

diego.jimenez@usach.cl

\section{ALDO BARRIA JORQUERA}

Pontificia Universidad Católica de Chile, Chile

ajbarria@uc.cl

https://doi.org/10.46468/rsaap.14.2.A6

¿Cómo influye la participación de grupos insurgentes vinculados al narcotráfico sobre los procesos de paz? Este artículo tiene como objetivo resolver dicha interrogante analizando dos casos de estudio: las negociaciones del Caguán (1998-2002) y de La Habana (2012-2016). En agosto de 2016, el expresidente Santos firmó un histórico acuerdo de paz con las Fuerzas Armadas Revolucionarias de Colombia (FARC), poniendo término a medio siglo de conflicto. En este sentido, las ganancias provenientes del tráfico de drogas, como fuente de financiamiento, obstaculizaron el arribo a una solución negociada con el gobierno de Pastrana, tornándose un asunto crucial durante las conversaciones desarrolladas en Cuba. Los casos ya señalados se compararán con la ayuda del Triángulo de Paz como herramienta analítica, buscando mostrar los cambios en el comportamiento y actitudes de sus protagonistas sobre el vínculo fariano con el narcotráfico.

* Artículo recibido el 17 de septiembre de 2019 y aceptado para su publicación el 14 de julio de 2020

** Los autores agradecen el aporte de dos evaluaciones anónimas a una versión previa de este artículo. 


\section{Introducción ${ }^{1}$}

En septiembre de 2017, Donald Trump amenazó con descertificar a Colombia en materia de antinarcóticos por el explosivo aumento de cultivos de coca durante los últimos años ${ }^{2}$. $\mathrm{Al}$ respecto, sostuvo que los avances en la lucha contra el narcotráfico se habían sacrificado en aras de negociar con las Fuerzas Armadas Revolucionarias de Colombia (FARC), responsabilizándolas por el incremento. Sus declaraciones apuntaban a los coletazos de una reconfiguración del narcotráfico en las zonas de influencia del ex grupo insurgente en medio de las conversaciones. Tras el desarme, se generaron expectativas en los campesinos de recibir mayores beneficios gubernamentales en contraprestación a la sustitución voluntaria de cultivos ilícitos, incitándolos a sembrar más coca.

Ante tal escenario nace la siguiente pregunta: ¿Cómo influye el involucramiento de grupos insurgentes vinculados al narcotráfico sobre los procesos de pacificación? Este artículo tiene como objetivo resolver dicha incógnita empleando como casos de estudio los diálogos del Caguán (19982002) y de La Habana (2012-2016) ${ }^{3}$. En agosto de 2016, el expresidente Juan Manuel Santos firmó un histórico acuerdo de paz con las FARC, poniendo término a medio siglo de conflicto armado. En esta línea, cabe señalar que las ganancias provenientes del tráfico de drogas, como fuente de financiamiento, obstaculizaron el arribo a una solución negociada con el gobierno de Pastrana. Por ende, su nexo con esta economía ilícita se tornó un asunto crucial en las conversaciones desarrolladas en Cuba.

De esta manera, este trabajo plantea, a partir del Triángulo de Paz, un análisis comparado de la influencia que tuvo el vínculo de la ahora desmovilizada insurgencia con el narcotráfico durante el proceso de paz en dos casos específicos: "Los diálogos del Caguán (1998-2002) y "Los diálogos de La Habana" (2012-2016). Igualmente, cabe subrayar que la relevancia de esta investigación es doble. Por un lado, busca llenar un vacío de

\footnotetext{
1 Este artículo es resultado del proyecto "Agendas criminales y procesos de paz en América Latina: Un estudio comparado entre Colombia y El Salvador", financiado por la Agencia Nacional de Investigación y Desarrollo (ANID).

2 El gobierno colombiano recibió este ultimátum por última vez en los 90, cuando el expresidente Ernesto Samper fue acusado de financiar su campaña con dinero del Cartel de Cali, el mayor exportador nacional de cocaína por ese entonces (Briscoe, 2017).

3 El proceso de las negociaciones del Caguán comienza, informalmente, el 15 de julio de 1998 con la reunión de Víctor G. Ricardo como el Alto Comisionado por la Paz designado por Andrés Pastrana y Manuel Marulanda Vélez, conocido como “Tirofijo”. Tras varias reuniones, se proclama oficialmente la apertura de negociaciones el 7 de enero de 1999. El proceso concluye oficialmente el 20 de febrero de 2002. Por otra parte, las negociaciones de La Habana comenzaron oficialmente el 4 de septiembre de 2012 y finalizaron el 24 de agosto de 2016.
} 
conocimiento académico sobre la sostenibilidad de los procesos de paz. Y por el otro, pretende contribuir a los estudios de paz abordando, de manera inédita, la relación existente entre estupefacientes y resolución de conflictos armados. El texto se estructura en cinco secciones. En la primera, se desarrolla una discusión bibliográfica sobre el nexo existente entre conflictos armados y narcotráfico. El segundo apartado se focaliza en el diseño metodológico. A continuación, se exploran los procesos de paz desarrollados en el municipio caquetense y la capital cubana con la ayuda del Triángulo de Paz, buscando dar cuenta de los cambios en el comportamiento y actitudes de sus protagonistas sobre la participación de las FARC en el narcotráfico. Finalmente, se presentan las conclusiones.

\section{¿Convergencia inesperada? Narcotráfico y conflicto armado}

La relación entre conflictos armados y drogas se ha vuelto cada vez más evidente durante las últimas décadas. No es casualidad que los mayores productores a nivel mundial sean naciones afectadas por beligerancias, tales como Afganistán, Myanmar y Colombia (UNODC, 2018). Bajo esta lógica, Cornell (2007) plantea que las confrontaciones armadas estimulan, agravan y, ocasionalmente, transforman los patrones preexistentes de producción de narcóticos. En efecto, la evidencia sugiere que la magnitud de dicha producción está directamente vinculada a su prolongación (Ross, 2004). Empero, la naturaleza de este vínculo aún no se ha definido con precisión.

Una primera aproximación proviene de la literatura clásica representada por Collier (2006), quien argumenta que los grupos insurgentes pueden involucrarse en un conflicto armado impulsados ya sea por la codicia o la queja, considerándolas mutuamente excluyentes. No obstante, esta visión ignora la posibilidad que sus estructuras motivacionales cambien en el tiempo, asumiendo implícitamente que son estáticas. O sea, los rebeldes estarían motivados únicamente por avaricia o agravio durante toda la confrontación. Por lo tanto, este enfoque supone la existencia de una clara distinción entre violencia criminal y violencia política, tendiendo a concebir a la criminalidad y la insurrección como fenómenos contrapuestos: los subversivos, en cuanto tipo ideal, luchan por una meta política autodefinida que sirve a un bien común mayor, mientras que las organizaciones criminales tienen ánimo de lucro (Phillips, 2015).

Sin embargo, durante la última década se ha desarrollado un cuerpo teórico que pretende complementar aquel enfoque encabezado por Makarenko (2008), quien postula la existencia de un nexo crimen-insurgencia impulsado por dos fenómenos: a) el descenso de la financiación estatal para la insurgen- 
cia, y b) la expansión del crimen organizado transnacional. El fin de la Guerra Fría redujo drásticamente la disponibilidad de financiamiento para rebeldes. Sin el enfrentamiento bipolar, el simple hecho de oponerse a un régimen político-ideológico no concitaba el apoyo económico de alguna superpotencia. Ante este escenario, los grupos insurgentes necesitaron encontrar otras fuentes de financiación para sobrevivir (Shaw y Mahadevan, 2018). Las actividades ilícitas emergieron como una lucrativa fuente de financiamiento para solventar su esfuerzo revolucionario. Por lo tanto, el nexo crimen-insurgencia supone que la guerra es criminogénica, en tanto crea oportunidades para desarrollar economías ilícitas y, a su vez, éstas promueven el conflicto armado ${ }^{4}$, configurando un círculo vicioso (Comolli,2018).

Ahora bien, resulta preciso indicar que este vínculo evoluciona, adoptando la forma de un continuum, con el crimen situado en el extremo izquierdo y la insurrección ubicada en el costado derecho en tanto fenómenos distintos, separados y lejanos conforme al entorno en el que operan, pudiendo ocurrir entre ambos una amplia gama de interacciones como se observa en la Figura 1. Desde este ángulo, cabe destacar que en la mitad del recorrido se encuentra un punto denominado convergencia motivacional, donde un grupo insurgente adopta estrategias criminales y políticas, de manera simultánea e intercambiable, a la vez que son dos extremos de un espectro en el marco de un conflicto armado (Makarenko, 2008).

\section{FIGURA 1}

\section{Continuum Crimen-Insurgencia}

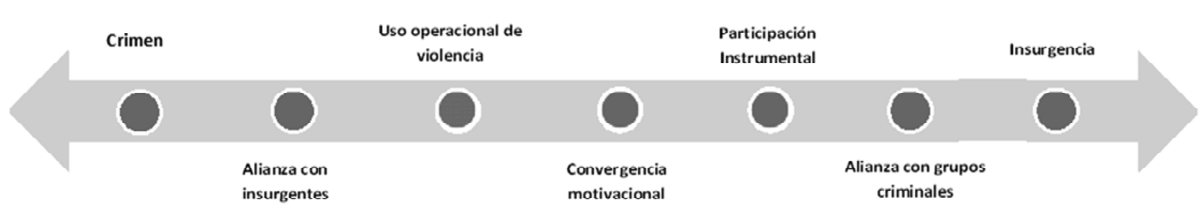

Fuente: Elaboración propia a partir de Makarenko (2008).

Su aporte es particularmente útil a fin de comprender por qué el narcotráfico y la guerra han quedado entrelazados, yendo más allá de esta dualidad, aprehendiendo las múltiples, complejas y cambiantes relaciones entre rebeldes y economías ilícitas. En esa línea, un valor agregado del

$4 \quad$ Entre 2000 y 2017, más del 60\% de las 1.113 resoluciones emitidas por el Consejo de Seguridad de Naciones Unidas han exigido respuesta ante las economías ilícitas. Este dato ilustra cómo el crimen organizado se ha tornado un factor clave para comprender la evolución de los conflictos armados contemporáneos. (GIATOC, 2018:5-6). 
continuum radica en que permite observar la evolución de una insurgencia a lo largo del conflicto armado. Así, es posible sostener que su participación en mercados ilícitos impulsada por la necesidad de financiar su guerra contra el régimen político-ideológico vigente puede afectar profundamente sus medios y estrategias e, incluso, en algunas circunstancias, sus objetivos e identidades, viéndose de este modo la suplantación del componente ideológico de un movimiento insurreccional por sus actividades ilícitas.

Igualmente, cabe subrayar que el nexo crimen-insurgencia no solo afecta la evolución del conflicto armado y el devenir del grupo insurgente que participa en el mismo, sino también incide en un eventual proceso de pacificación. En efecto, la participación de rebeldes en el narcotráfico generaría una feliz irresolubilidad, o sea, un aceptable, pero inestable statu quo donde existen fuertes incentivos para mantener el conflicto en ebullición, siendo difícil lograr un acuerdo negociado o victoria militar (Crocker, Osler \& Aal, 2005). Esta situación paradójica es atribuible básicamente a dos factores interconectados.

En primer lugar, las ganancias obtenidas del narcotráfico robustecen a los grupos insurgentes, pues aumentan sus capacidades de reproducirse materialmente y construir instituciones en sus zonas operativas, dificultando cada vez más su derrota militar. Desde este ángulo, Keen (1998) sostiene que la guerra provoca un sistema alternativo de beneficios, poder e incluso protección, pues el Estado se debilita, viéndose imposibilitado de ejercer su autoridad sobre el territorio, y aquel vacio de poder es llenado por rebeldes. Así, el tráfico de drogas permite a grupos subversivos no solo comprar armas o entrenar combatientes, sino también proporcionar bienes y servicios a comunidades que participan en esta economía ilícita como medio de subsistencia, recibiendo a cambio protección, lealtad y cooperación de la población (Dudouet y Galvanek, 2018). Por ello, los guerrilleros actúan como constructores competitivos de Estado, mermando su funcionalidad y legitimidad. Ergo, mientras más orden y seguridad brinden a las comunidades, mayor es la posibilidad de convertirse en protoestados de facto con un alto grado de capital político ${ }^{5}$.

En segundo lugar, los flujos de ingresos ilícitos asociados al tráfico de drogas conducen al aplazamiento de la paz, ya que los insurrectos se benefician económicamente de la continuación del enfrentamiento, pudiendo incluso actuar como spoilers ${ }^{6}$, tendiendo a subvertir los procesos de pacifica-

\footnotetext{
$5 \quad$ El capital político consiste en la percepción de legitimidad (confianza de la población que las acciones de los criminales son beneficiosas y justificadas) y apoyo popular (provisión voluntaria de la población de suministros, refugio, e inteligencia) (Felbab-Brown, 2010:6-7).

6 El concepto spoiler fue elaborado originalmente por Stedman para describir actores que usan violencia para oponerse, debilitar, o manipular procesos de paz (Stedman, 1997:8).
} 
ción que intenten llevarse a cabo, incrustando sus agendas criminales ${ }^{7}$ dentro de los acuerdos alcanzados (Cockayne, Boer y Bosetti, 2017). En este sentido, Boer y Bosetti (2015) consideran que uno de los principales motivos para explicar la prolongación de las guerras es la disponibilidad y explotación de una fuente fiable de financiación. Como el narcotráfico es inherentemente ilícito en el régimen internacional vigente, no es factible ofrecer a rebeldes una alternativa que les permita mantener el control sobre ese mercado. Justamente en este punto gravita la diferencia entre los narcóticos y otros recursos naturales, tales como diamantes o madera. Por ende, una reparación a las quejas expresadas originalmente por los insurgentes será de poca utilidad para terminar el conflicto cuando sus estructuras motivacionales, estrategias y objetivos se hayan criminalizado.

No obstante, Jonsson, Brennan y O'Hara (2016) argumentan que la incidencia del involucramiento de rebeldes en el narcotráfico sobre la resolución de conflictos armados no es siempre uniforme ni negativa. De este modo, el resultado se encuentra condicionado por la política estatal de drogas y la actitud del grupo rebelde frente a esta economía ilícita. Así, es posible prever cuatro escenarios que pueden presentarse durante las etapas por las que atraviesa una confrontación.

La primera coyuntura es sostener una guerra contra el narcotráfico, en donde las autoridades mantienen una línea dura contra el tráfico de drogas, a la vez que la insurgencia busca continuar beneficiándose del mercado, constituyendo un obstáculo para iniciar un proceso de paz, y dando pie a la continuación de la guerra con el fin de suprimir su financiamiento ilícito. Otra situación hipotética es ofrecer un soborno por la paz, bajo la cual el Estado adopta un enfoque permisivo frente al tráfico de narcóticos y donde las ganancias mal habidas están implícitamente aceptadas, repartiéndolas entre los rebeldes con el único propósito de estimular su participación en el proceso de paz. La tercera posibilidad consiste en cooperar con el cambio, en la cual el Estado mantiene un enfoque restrictivo, pero los insurrectos no están en interesados en seguir beneficiándose del narcotráfico, dando pie a una "colaboración para el cambio", pudiendo incluso apoyar los esfuerzos por combatir el narcotráfico a cambio de concesiones durante la negociación. Finalmente, encontramos un contexto de apatía total, bajo el cual el Estado aplica una política de drogas permisiva pero los rebeldes no desean obtener ganancias del narcotráfico, no siendo este último fenómeno un impedimento para llevar a cabo las negociaciones.

Agendas criminales se refiere a un programa o plan subyacente de naturaleza criminal celebrado por actores que compiten por el gobierno y gestión pública de recursos de un Estado. Pueden ser adoptadas por una amplia gama de actores, desde grupos criminales, insurgentes, empresas, funcionarios públicos o dirigentes políticos (Boer y Bosetti, 2017:9). 


\section{Diseño metodológico}

Resulta oportuno indicar que ambas negociaciones entre el Estado colombiano y las FARC ejemplifican la relación existente entre narcotráfico y resolución de conflictos, haciéndolo teóricamente relevante para los fines de esta investigación. En agosto de 2016, el expresidente Juan Manuel Santos firmó un histórico acuerdo de paz con las FARC que puso término a la confrontación armada más antigua del hemisferio. Esta prolongación obedeció, en gran parte, a que la intensa participación de los farianos en el narcotráfico no solo proporcionó cuantiosos recursos para expandir su capacidad militar, sino también un alto grado de capital político, desincentivándolo a alcanzar una solución negociada con el gobierno durante los diálogos del Caguán (1998-2002). Luego, el tráfico de drogas se convirtió en un tema crucial durante el proceso de paz de La Habana (2012-2016).

Atendiendo a lo expuesto, es necesario establecer que la metodología a emplear en el presente trabajo es el estudio de casos. Bajo esa lógica, conviene aclarar que se trata de un estudio de caso sincrónico-diacrónico, por cuanto examina un lapso acotado (1998-2016) y en profundidad, de forma tal que el concurso de actores estatales y no estatales solo son analizados en cuanto a su relevancia desde los casos seleccionados en el periodo antes señalado (Gerring, 2007). Asimismo, el problema de investigación se estudia a partir de acontecimientos sobre los que no se tiene control y con un enfoque holístico en tanto se estudia la unidad de observación en su totalidad, sin una muestra definida. Por lo tanto, esta investigación posee un carácter no experimental que, por su dimensión temporal, es clasificada como transeccional, pues pretende evaluar cuál es el nivel o estado de diversas variables en un momento determinado.

Posteriormente, cabe señalar que la herramienta analítica a utilizar consiste en el Triángulo de paz. Para comprender cabalmente esta herramienta es relevante considerar, primeramente, que definir el concepto paz resulta complejo dado su carácter polisémico. Empero, la literatura especializada nos remite a una distinción entre dos acepciones. Por un lado, encontramos una visión restringida del término, que alude a la ausencia de guerra y violencia directa (aquella ejercida o aplicada por un actor), también conocida como paz negativa (Galtung, 1996). Bajo esta lógica, no se descarta la existencia de conflictos en una sociedad, siendo comprendida la paz negativa como un estado donde múltiples actores pueden tener relaciones antagónicas, expresadas en enfrentamientos que excluyen el uso de violencia armada, sistemática y organizada. Así, pueden ocurrir episodios de violencia esporádica originados a partir de los mismos, sin que ello constituya una guerra.

La fortaleza metodológica que presenta esta conceptualización radica en que permite su cuantificación, basándose netamente en métricas o 
indicadores, siendo fácilmente medible. Desde este ángulo, la paz puede ser observada en un país, por ejemplo, a través del índice de letalidad registrado cada año. Empero, esa noción ha sido cuestionada por dos motivos. En primer lugar, su estrechez conduce a interpretaciones reduccionistas, en tanto las relaciones podrían únicamente ser descritas como pacíficas o conflictivas. En segundo lugar, esta concepción carece de poder explicativo sobre la naturaleza, solidez o sostenibilidad de la paz (Diehl, 2016).

En respuesta a este vacío surge un enfoque alternativo: paz positiva. Una definición holística que contempla la ausencia de violencia indirecta o estructural (aquella que no es ejercida o aplicada por un actor), expresada en la existencia de justicia social, relaciones cooperativas y plena vigencia de los derechos humanos. O sea, al delimitar sus rasgos específicos, este concepto busca ahondar en factores que contribuyen a la solidez de la paz, contraponiéndose a su sentido negativo. Desde esta óptica, Wallensteen y Joshi (2018) señalan que la paz positiva puede ser operacionalizada mediante cinco dimensiones analíticas: (1) bienestar; (2) calidad de las relaciones; (3) resolución de conflicto; (4) acceso a recursos, equidad y seguridad humana; y (5) capacidad institucional. Así, estos elementos permiten clasificar a un Estado como pacífico en términos de paz positiva.

Luego, esta visión ha sido blanco de críticas, porque la incorporación de dimensiones tales como justicia social o derechos humanos ensancha el objeto de estudio de la disciplina, al punto que el concepto paz pierde por completo su utilidad como categoría analítica, generándose así un estiramiento conceptual (Sartori, 2011) ${ }^{8}$. Ante este emplazamiento, los partidarios de una paz positiva indican que la "mera ausencia de guerra puede ser compatible con situaciones en las que estén vigentes statu quo profundamente autoritarios e injustos que tarde o temprano llevarían a un estallido violento" (Harto, 2016:130). Por tal motivo, estiman necesario comprender las causas de los enfrentamientos armados, analizando cómo se puede desarrollar una paz sostenible, y cuáles factores pueden prevenir la reaparición de la violencia.

A raíz de lo ya planteado, es posible sostener que entre paz negativa y paz positiva existe una relación contradictoria, no abarcando la totalidad de interacciones existentes al interior de una sociedad. Tampoco son categorías mutuamente excluyentes, más bien representan los polos de un espectro. En esta graduación existe un área gris compuesta por situaciones que, si bien no tienen visos bélicos, no podrían ser catalogadas como pacíficas,

Este concepto consiste en la necesidad de establecer un concepto que pudiera ser lo suficientemente amplio para abarcar una cantidad significativa de casos, a fin de generalizar los resultados de las investigaciones en ciencia política, previniendo que aquel concepto sean tan general que no tenga significado alguno. A la inversa, hay que evitar que el concepto sea tan restringido que no admita generalización alguna. 
tales como cese al fuego, tregua, o procesos de paz . Pretendiendo capturar esa diversidad de escenarios nace el concepto de paz imperfecta, el que alude a "espacios e instancias en las que se pueden detectar acciones que crean paz, a pesar de que están en contextos en los que existen conflictos y violencia” (Muñoz, 2010:47). En efecto, este neologismo recoge la bidimensionalidad de la paz (negativa y positiva), centrándose en medidas para prevenir la violencia directa y mitigar la violencia estructural.

Desde esa perspectiva, cabe subrayar el aporte realizado por Höglund y Söderberg (2010), quienes, para operacionalizar la naturaleza de los procesos de paz, diseñaron una herramienta analítica conocida como Triángulo de Paz, el cual está basado en el Triángulo del Conflicto que los analiza a partir de tres dimensiones: conflicto en sí, comportamiento y actitudes. Así, el conflicto en sí se refiere a los problemas, posiciones y demandas de los actores involucrados. En tanto, el comportamiento apunta a sus conductas y la manera en que persiguen sus demandas durante el conflicto. Finalmente, las actitudes abarcan las emociones y percepciones hacia los otros, hacia sus propias metas y hacia al conflicto en sí mismo. Cabe mencionar que los tres vértices se condicionan mutuamente. A su vez, cada vértice posee su propia dinámica.

\section{FIGURA 2}

Triángulo de Paz

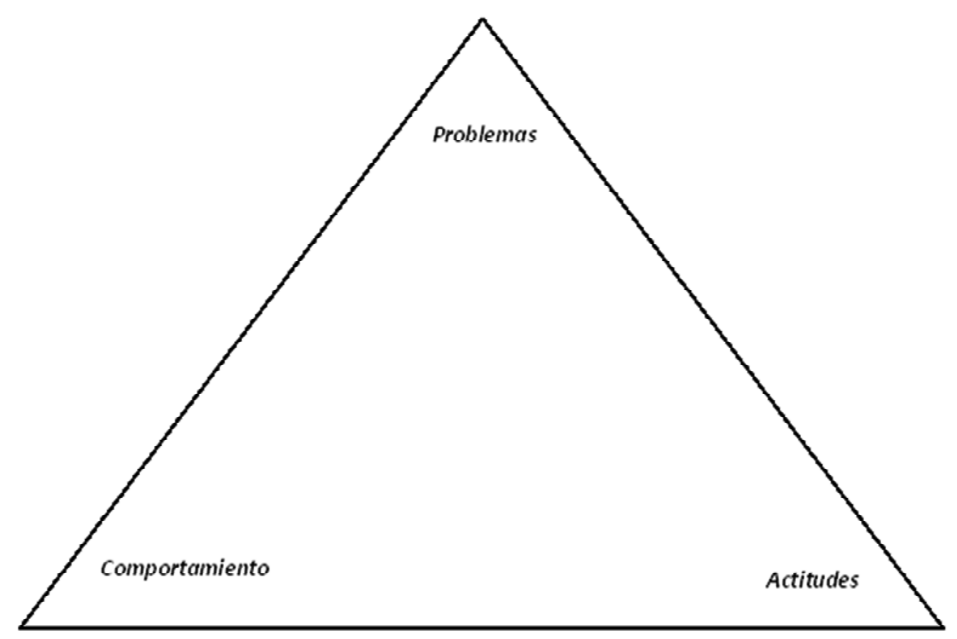

Fuente: Elaboración propia a partir de Höglund y Söderberg (2010).

9 "Procesos de paz" se define como un esfuerzo dirigido a finalizar un conflicto entre diferentes actores a través del diálogo y de medios no violentos. Sus objetivos y formas 
Como se aprecia en la Figura 1, los vértices que componen el Triángulo de paz son los problemas, comportamientos y actitudes. Los problemas se refieren a los asuntos o temáticas en juego para los protagonistas de la confrontación. El segundo vértice (comportamiento) se asocia a la relativa presencia o ausencia de violencia en su abordaje durante el proceso de paz o postconflicto. Finalmente, el tercer elemento (actitudes) constituye un indicador sobre la relativa presencia o ausencia de actitudes conflictivas en el proceso de paz. Por lo tanto, el Triángulo de Paz enriquece el análisis de las variantes empíricas de un proceso de paz.

Respecto de la extensión de ambas negociaciones entre el gobierno y las FARC, sus respectivas dinámicas no serán analizadas exhaustivamente, prestando atención solo a sus hitos. Posteriormente, los datos obtenidos serán contrastados con los vértices del Triángulo de Paz. Resta mencionar que la investigación se apoyará en fuentes secundarias para analizar los diálogos en El Caguán y La Habana, particularmente bases de datos nacionales e internacionales, tales como el Centro de Recursos para el Análisis de Conflictos (CERAC) y el Programa de Datos sobre Conflictos de la Universidad de Uppsala (UCDP). Asimismo, se examinarán reportes elaborados por organismos no gubernamentales, tales como Crisis Group, Centro Noruego para la Resolución de Conflictos (NOREF) y Escola de Cultura de Pau. Igualmente, se recabará información mediante fuentes primarias tales como la Oficina del Alto Comisionado para la Paz, entidad responsable de asesorar al gobierno colombiano en la formalización de los diálogos y acuerdos de paz. Por último, se consultarán fuentes terciarias hemerográficas, tales como Council on Foreign Relations y Washington Office on Latin America.

\section{El Caguán y La Habana a la luz del Triángulo de paz: el problema}

Según el Instituto de Estudios sobre Guerra de la Universidad de Hamburgo, la confrontación entre las FARC y el Estado colombiano puede ser catalogada como una guerra antirrégimen prolongada y de alta intensidad, la cual mutó en el tiempo, pasando de reducidos puntos geográficos a expandirse en diversos frentes y a beneficiarse de economías ilícitas para ampliar su financiación y alcance (AKUF, 2018). Originalmente, las FARC se erigieron como un grupo de autodefensa durante "La Violencia" (1948-

pueden variar, desde la negociación de un alto el fuego bilateral, la interrupción de violencia homicida y, en algunos casos, la firma de un acuerdo de paz. Son parte de un acuerdo político que representa la negociación sobre el acceso a recursos estatales y concesiones políticas, sociales, económicas y judiciales a cambio de poner fin a la violencia y hostilidades (Boer y Bosetti, 2017:9) 
1958). Pronto se convirtieron en un movimiento insurreccional que discrepaba fuertemente con la naturaleza del sistema político y económico. Su objetivo principal era instaurar un régimen marxista basado en el socialismo que resolvería las injusticias y redistribuiría la riqueza en el país andino (Felter y Renwick, 2017).

Durante sus primeras dos décadas, la intensidad del conflicto armado fue baja dado que las FARC no representaban una amenaza seria. En efecto, los 60 y principios de los 70 fueron años de supervivencia para los farianos, siendo apenas una milicia de base campesina, que contaba con escasos recursos, bajo entrenamiento, una logística restrictiva, y sin una estrategia definida que operaba solo en áreas donde la presencia estatal era frágil o inexistente, como las regiones montañosas y selváticas (UCDP, 2018).

No obstante, esta situación cambió radicalmente con la celebración de la VII Conferencia (1982), momento en que el Secretariado aprobó la explotación del narcotráfico para sostener su plan estratégico y, así, doblar la cantidad de frentes, aumentar su equipamiento militar y tomar el poder en ocho años (Pécault, 2008). Desde este ángulo, resulta oportuno precisar que los líderes guerrilleros consiguieron subordinar las actividades criminales a sus objetivos políticos de forma pragmática. Este elemento permitió a las FARC hacer un uso sistemático del narcotráfico, así como otras economías ilícitas para financiar la guerra sin que la unidad de mando y el compromiso ideológico de la tropa se descompusieran.

Empero, en la práctica, la participación de las FARC en el narcotráfico generó problemas de organización. Las tensiones y fracturas internas emergieron cuando la dirigencia acusó a algunos cuadros medios de estar demasiado involucrados en la actividad ilícita y participar poco en el trabajo político (Boer, Garzón y Bosetti, 2017). En efecto, las preocupaciones giraban en torno a que la identidad y objetivos del grupo estaban siendo eclipsados por la codicia. Esta perspectiva, muy en sintonía con el nexo crimeninsurgencia propuesto por Makarenko (2008), reconoce que las FARC surgieron sobre la base de agravios políticos, pero a lo largo del tiempo su estructura motivacional se transformó gracias a sus vínculos con el tráfico de drogas.

$\mathrm{Al}$ respecto, Villalobos (2011) señala que un movimiento insurrecto que contaba con un proyecto político-ideológico mutó en una narco-guerrilla producto de un proceso de descomposición social, moral y político en sus filas, lo cual resultó natural por tratarse de una degradación de insurrección a criminalidad, pasando de una lógica combativa a una depredadora. Luego, el autor indica que la prolongación de un conflicto armado termina convirtiendo la violencia criminal en un oficio per se sin conexión con los fines políticos iniciales. La frontera entre crimen organizado y actor político 
se borró por completo: el discurso ideológico finalmente sirvió para justificar la criminalidad como modo de vida. Incluso, su comandante principal Rodrigo Londoño Echeverri, alias "Timochenko", admitió que "la lucha interna que libramos, desde el punto de vista ideológico para que los guerrilleros no se dejen absorber por los valores que promueve el narcotráfico es muy grande, y con algunos cuadros la hemos perdido" (Crisis Group, 2014:4).

Vale recordar que, originalmente, las FARC prohibieron que se cultivara coca por motivos ideológicos en los territorios controlados por aquellas fuerzas, percibiéndola como la máxima expresión del capitalismo decadente. Incluso intentaron erradicarla, política que suscitó un rechazo generalizado del grupo insurgente, pues la población dependiente de los cultivos ilícitos como medio de subsistencia se sintió agraviada por la injerencia de las FARC. Tras algunos años, durante los cuales las FARC no lograron un apoyo estable entre la población, llegaron a la conclusión de que no podían mantener la prohibición de los cultivos ilícitos. En esas circunstancias se vieron obligadas a cambiar progresivamente su postura, pasando del rechazo inicial a tolerarlos, para después gravarlos con impuestos y, por último, regular tanto el cultivo como su procesamiento (McQuinn, 2016). De este modo, los farianos fueron capaces de presentarse a sí mismos no solo como un movimiento revolucionario, sino también como protectores de las comunidades marginadas, rol que les permitió obtener una alta cuota de capital político, al punto de instaurar una Rebelocracia ${ }^{10}$ en las zonas bajo su dominio.

El alcance exacto de la participación de las FARC en las economías ilícitas sigue siendo un tema de debate. Según una estimación realizada por Shaw, Nellemann y Stock (2018), recaudaban anualmente US\$600 millones, convirtiéndolas en la tercera organización insurgente más adinerada del planeta. Así, las rentas ilícitas constituían el corazón de los farianos. Para entender el porqué es importante analizar la estructura financiera de la guerrilla de impronta marxista-leninista. A diferencia de organizaciones criminales tradicionales, las ganancias de las FARC fluían de abajo hacia arri$\mathrm{ba}^{11}$. Los numerosos frentes, columnas móviles y unidades tácticas se autofinanciaban y entregaban el dinero al bloque, que a su vez alimentaba al Estado Mayor y al Secretariado. Particularmente en el caso del narcotráfico,

10 En el contexto del conflicto armado colombiano, Ana Arjona utiliza el neologismo Rebelocracia (Rebelocracy) para describir una situación donde grupos guerrilleros imponen un conjunto de reglas que estructuran la interacción humana en una comunidad en tiempos de guerra, convirtiéndose en gobernantes de hecho (Arjona, 2016:137).

11 Las FARC dividen sus ganancias en tres niveles. En el primer nivel se encuentran los recursos necesarios para cumplir con sus planes estratégicos (es decir, las proyecciones de crecimiento y ocupación territorial). En el segundo nivel está el sostenimiento de estructuras como frentes y compañías. En el tercero, la supervivencia, es decir la caja menor de las milicias (Garzón, 2015:9). 
si se suma el dinero obtenido por el tributo al cultivo de coca o "gramaje" (US $\$ 67,9$ millones), los ingresos de la producción de cocaína (U\$S169,5 millones) y otros impuestos sobre el trasiego (US\$30 millones), las FARC habrían obtenido US\$267 millones anuales por el comercio de cocaína. Empero, McDermott (2017) considera que fueron ineficientes en su manejo del tráfico de estupefacientes, pues el Secretariado por motivos políticos siempre se mantuvo distanciado del tráfico de drogas, delegando esta responsabilidad a los frentes, como veremos luego.

Fue así como el narcotráfico se convirtió en el eje económico de su revolución, pues permitió a la guerrilla convertirse en una fuerza de gran alcance, con capacidad suficiente para sostener una guerra prolongada. Las ganancias ilícitas permitieron aumentar su capacidad de lucha sustantivamente. En 1979, tres años antes de su decisión de abrazar el narcotráfico como fuente de financiamiento, las FARC poseían solo nueve frentes. En 1986, contaban con 3.600 combatientes en treinta y dos frentes, y para 1995, unos 7.000 combatientes en sesenta frentes. Cinco años después, la fuerza de las FARC se duplicó, llegando a 14.000 combatientes en más de setenta frentes (Felbab-Brown, 2010:81).

Por consiguiente, se puede sostener que el crecimiento de las FARC y el aumento de los cultivos de coca en Colombia durante los 90 y los 2000 siguieron trayectorias paralelas. En efecto, la guerrilla de inspiración marxista-leninista nunca estuvo tan próxima a lograr su cometido de crear un equilibrio estratégico con el Estado para tomar el poder como sucedió en esta fase, gracias a la instrumentalización del narcotráfico. De hecho, llegó a ser percibida como una grave amenaza para el gobierno central, así como para las élites tradicionales y los carteles operativos en el país andino, quienes comenzaron a crear grupos paramilitares o autodefensas para combatir al ex ejército revolucionario. Esto sirvió de poco para detener la actividad fariana, pues solamente generó un recrudecimiento de la violencia armada.

\section{Comportamiento}

Aunque el conflicto armado ha sido extenso, una serie de intentos de negociación con las FARC se realizaron en distintas administraciones para finalizarlo, siendo una especie de ensayo y error. Los esfuerzos por alcanzar la paz tuvieron su punto más álgido durante el mandato de Andrés Pastrana (1998-2002), quien mantuvo su promesa electoral de buscar una salida política al conflicto armado. A fines de 1998, inició los llamados "diálogos del Caguán", creando como gesto de buena voluntad una zona de distensión (área desmilitarizada) ubicada en la región de Caguán. No obstante, fracasaron, entre otras razones, por la desconfianza mutua entre el gobierno y la guerrilla. 
Las negociaciones estaban condenadas desde su inicio, ya que podría decirse que ni las FARC ni el Gobierno perseguían honestamente un arreglo negociado. Por su parte, las FARC, situadas en la cúspide de su poder militar, aprovecharon los diálogos para avanzar en su proyecto político-estratégico, cuyo objetivo era transitar de una guerra de guerrillas a una guerra de movimientos. Así, congelaron unilateralmente las negociaciones varias veces y la zona de distensión se convirtió en un estado de facto fariano, siendo utilizado para ampliar el cultivo de coca, reclutar miles de soldados, construir un centro de mando, comprar armas, y ocultar secuestrados (Felbab-Brown, 2010:88).

Las Fuerzas Armadas colombianas, por el contrario, estaban mal entrenadas, mal equipadas y desmoralizadas. Pastrana entendía que la guerrilla podía fortalecerse durante el proceso de paz, por lo que no podía permitirse el lujo de no modernizar su aparato militar y ceder más terreno. Durante las negociaciones, Pastrana cortejó mediante intensos esfuerzos diplomáticos a su homólogo estadounidense Bill Clinton para involucrarse más activamente en el conflicto, solicitando una "intervención por invitación" que implicaba aceptar la agenda antinarcóticos de Estados Unidos (basada en la interdicción y erradicación forzada) a cambio del apoyo militar, técnico y socioeconómico de Washington (Tickner, 2014). El resultado fue el Plan Colombia, un paquete de ayuda diseñado conjuntamente, cuyo objetivo era combatir la insurgencia, aumentar el control territorial, extender el Estado de derecho y perseguir el desarrollo socioeconómico colombiano (FelbabBrown, Trinkunas y Hamid, 2018:88-89).

Desde esta óptica, el Plan Colombia se fundamentó en que la relación entre farianos y el narcotráfico había adquirido un carácter simbiótico, haciendo a narcotraficantes e insurgentes virtualmente indistinguibles. Esto no es azaroso, toda vez que durante las últimas dos décadas Colombia ha sido el principal productor de cocaína en el planeta, y Estados Unidos su principal consumidor. Por esto Pastrana elaboró un discurso de corresponsabilidad en la lucha contra los rebeldes, suponiendo que a través del combate a las drogas ilícitas se atacaría el centro de gravedad económico de las FARC y, por lo tanto, se lograría el debilitamiento total de la guerrilla. Esta lógica permitió levantar las restricciones impuestas a la cooperación militar para utilizarla no solo como estrategia antinarcóticos, sino también bajo un enfoque contrainsurgente. De esta manera, el rol de la Casa Blanca se tornó intenso y a veces decisivo. Incluso funcionarios del Departamento de Estado se reunieron con miembros del Secretariado de las FARC en Costa Rica para expresar su visión sobre el proceso de paz y el combate al narcotráfico (Borda, 2013).

Finalmente, los diálogos con las FARC, que habían ocupado la mayor parte de su gestión, se interrumpieron en febrero de 2002 luego de que éstas 
secuestraran un avión. Acto seguido, Pastrana ordenó a las Fuerzas Militares recuperar el control de la zona de distensión y capturar a los principales líderes de la guerrilla. Mientras la primera condición se cumplió, la segunda no. Incluso, tras los atentados del 11-S, las FARC fueron rotuladas como una organización terrorista, amparándose en los criterios utilizados por el gobierno estadounidense. Desde entonces, se dio inicio a un renovado combate que se convirtió en una "guerra contra las drogas", generándose una escalada de violencia por ambas partes en conflicto con una pesada carga sobre la población civil (ver Gráfico 1). Tras las fallidas conversaciones de Pastrana, el fantasma de un eventual Estado fallido impulsó la necesidad de recuperar la capacidad, legitimidad y soberanía del Estado. La construcción de aquella imagen caótica produjo un cambio de enfoque, por cuanto su sucesor Álvaro Uribe (2002-2010) llegó a Casa de Nariño adoptando una línea dura de contrainsurgencia para diezmar la capacidad operativa de la guerrilla, en parte gracias a los recursos económicos transferidos mediante el Plan Colombia ${ }^{12}$.

\section{GRÁFICO 1}

Intensidad del conflicto armado colombiano (1998-2016)

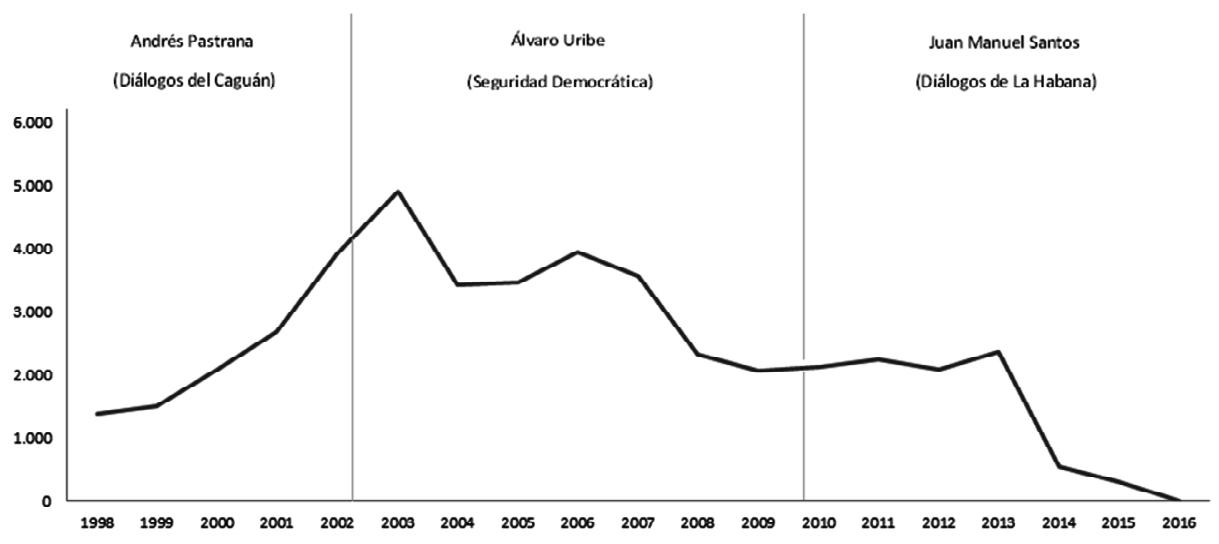

Fuente: Elaboración propia a partir de FIP, 2017 y CERAC, 2017.

Otro punto de inflexión se dio luego que Juan Manuel Santos (20102018) asumió la presidencia, pasando de la cartera de Defensa durante la era Uribe a negociar con las FARC, iniciándose así la diplomacia por la paz. En su discurso de investidura manifestó:

12 De los 9.9 billones de dólares inyectados entre 2000 y 2016, 6.9 billones (71\%) fueron invertidos en capacidades militares y policiales, mientras que solo 2.8 billones (29\%) fueron destinados a socioeconómicas e institucionales (Isacson, 2016). 
la puerta del diálogo no está cerrada con llave [...] yo aspiro, durante mi Gobierno, a sembrar las bases de una verdadera reconciliación entre los colombianos. A los grupos armados ilegales que invocan razones políticas y hoy hablan otra vez de diálogo y negociación, les digo que mi Gobierno estará abierto a cualquier conversación que busque la erradicación de la violencia, y la construcción de una sociedad más próspera, equitativa y justa (Fisas, 2017:103).

Una década después de las conversaciones realizadas por Pastrana, la correlación de fuerzas entre los actores en conflicto era muy diferente. En el anterior proceso de paz, los farianos se encontraban, a nivel militar, suficientemente desgastados para sentarse a conversar producto de la ofensiva, y su objetivo político de tomar el poder por las armas parecía cada vez más difícil de materializar. Mientras tanto, para el gobierno era razonable negociar, pues, aunque poseía capacidad militar suficiente para contrarrestar los esfuerzos realizados por la insurgencia, como resultado del proceso de modernización iniciado con Plan Colombia y profundizado durante la administración Uribe, no la había logrado derrotar. Entre 2002 y 2010 se destinó el 4\% del PIB al sector defensa. Igualmente, durante ese periodo, Colombia incrementó un $40 \%$ su pie de fuerza gubernamental. Por primera vez, los combates librados por el gobierno superaron a aquellos lanzados por las FARC, forzándolo a retomar tácticas de guerra de guerrillas y replegarse hacia zonas periféricas, caracterizadas por una extrema dependencia de cultivos ilícitos, agudizando así su tendencia a la narcotización (Ríos, 2016). Cabe resaltar que sus acciones bélicas cayeron abruptamente, pasando de 1.042 en 2002 a solo 724 en 2010 (ver Gráfico 2).

\section{GRÁFICO 2}

Acciones armadas FARC (1998-2016)

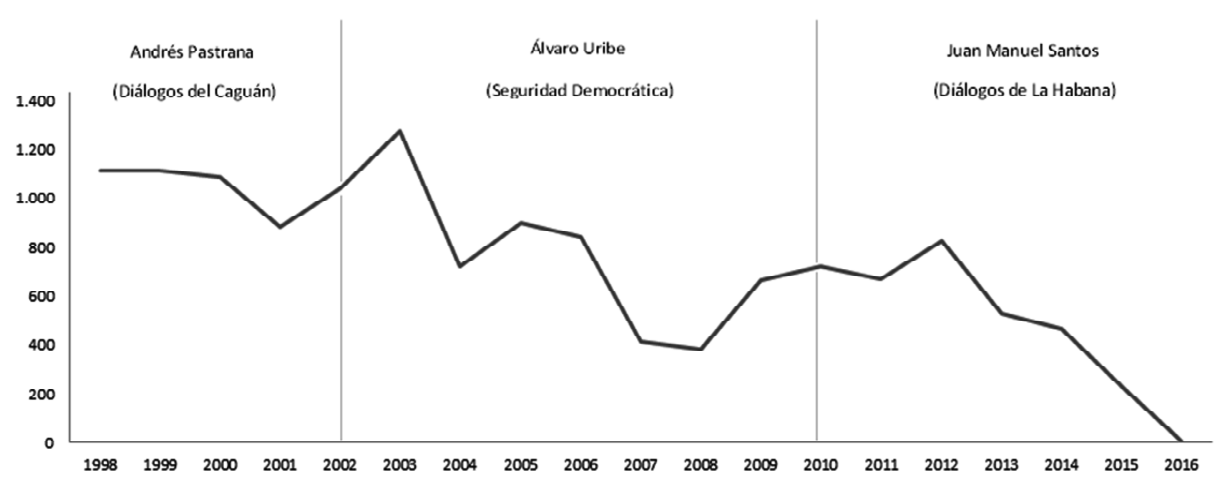

Fuente: Elaboración propia a partir de CERAC, 2017. 
Ante este escenario, las FARC trataron de recuperarse implementando el Plan Renacer y redoblaron esfuerzos en conservar sus reservas de capital político en aquellas regiones donde la guerrilla había jugado un rol en la estructuración de la vida social y económica mediante la provisión de bienes y servicios. Sin embargo, esto no bastó para reparar los lazos con las comunidades ni volver a sus niveles anteriores de poder e influencia territorial. En efecto, la puesta en marcha implicó un serio revés para las FARC, pues la descentralización operativa y táctica que promovió en los frentes para compensar el desbalance estratégico elevó su grado de autonomía, "dificultando el cierre de las brechas geográficas, financieras, logísticas e incluso ideológicas con el Secretariado, de esa forma que se siguiera ejerciendo un control más estricto desde la cúpula guerrillera" (Echandía, 2011:25-26).

Sobre este último punto es posible indicar que, sin proponérselo, esta estrategia parece haber influido en que las unidades más aferradas al narcotráfico se hayan fragmentado paulatinamente en función de la obtención de ganancias económicas derivadas de esta economía ilícita, las cuales en un proceso de paz no se desmovilizarían. Sin duda, este resultado podría transformar el conflicto, pues su dinámica estaría más en sintonía con la literatura económica centrada en la rebeldía movilizada por avaricia. La campaña gubernamental fue relativamente exitosa en términos militares porque dañó la operatividad nacional y el accionar armado de la guerrilla, obligándola a replegarse a regiones periféricas del territorio colombiano donde prevalecen los cultivos ilícitos. Empero, ésta continuó desarrollando su economía de guerra, ya que gran parte del esfuerzo revolucionario se enfocó en proteger estas nuevas áreas estratégicas a fin de continuar garantizando su financiamiento a través de la coca. En consecuencia, los réditos provenientes del narcotráfico se tornaron en un factor decisivo para explicar el alto nivel de resiliencia manifestado por los farianos durante la confrontación (Crisis Group, 2012).

A partir de lo ya expuesto, es posible señalar que existía un punto de estancamiento, donde proseguir con las mismas dinámicas de violencia, sin negociar, terminaría por generar consecuencias negativas, tanto para la ex guerrilla como para el gobierno. Los primeros contactos exploratorios, de carácter confidencial, se mantuvieron por varios meses durante 2011 en La Habana. Esta fase permitió construir una agenda y diseñar un conjunto de reglas que promovieren el diálogo. Ambas partes establecieron que se daría bajo los siguientes principios rectores: (a) aprender de los errores del pasado para no repetirlos; (b) cualquier proceso tiene que llevar al fin del conflicto armado; y (c) mantener las operaciones y presencia militar en territorio nacional. En septiembre de 2012, el gobierno colombiano y las FARC anunciaron oficialmente el inicio de conversaciones para alcanzar una solución 
pacífica al conflicto. En la capital cubana se incorporó el tema del narcotráfico en la agenda de negociación porque el gobierno colombiano y los farianos coincidieron, de manera inédita, en que si no se solucionaba el problema de las drogas ilícitas, o al menos su expresión territorial, no se sentarían las bases para construir una paz duradera y estable que permitiera implementar todos los acuerdos alcanzados. Reconociendo que:

- las causas subyacentes de la beligerancia no se relacionan con la aparición de cultivos ilícitos, o la producción y comercialización de narcóticos en el país andino;

- la producción de aquellos cultivos está vinculada, en parte, a la existencia de condiciones de pobreza, marginalidad, débil presencia institucional y existencia de organizaciones narcotraficantes; - el narcotráfico ha alimentado y financiado el conflicto armado. Por ende, entregar una solución definitiva, conjunta e integral al problema de las drogas ilícitas constituye un mecanismo de no repetición (OACP, 2018).

Los elementos mencionados denotan que el tema del narcotráfico jugó un papel radicalmente diferente en las últimas conversaciones en comparación con El Caguán, básicamente por dos razones interconectadas.

En primer lugar, mientras que en las anteriores conversaciones el ex presidente Pastrana se alineó con la "guerra contra las drogas", participando en el diseño del Plan Colombia a fin de fortalecer el aparato militar y combatir a las FARC, Santos adoptó un discurso más revisionista, convocando a un debate global destinado a realizar una evaluación objetiva de la actual estrategia antinarcóticos y avanzar en la construcción de consensos para emprender ajustes, con lo cual el enfoque restrictivo clásico del gobierno colombiano se amplía con la presidencia de Santos (Bitar y González, 2018).

En relación con lo anterior, Santos optó por modificar la postura oficial sobre el nexo entre las FARC y el tráfico de estupefacientes, distanciándose así de Pastrana. Tanto el ex mandatario como sus plenipotenciarios en la mesa de negociaciones enfatizaron en que no eran una organización narcotraficante, y que por eso estaban dialogando con ella. Así, el gobierno se apartó de la visión imbuida en el Plan Colombia sobre la dinámica del conflicto armado, desarrollando el proceso de paz habanero a partir de la siguiente premisa subyacente: los farianos son beligerantes políticos con algunos vínculos ilícitos que podían quebrarse si el Estado ofrecía incentivos adecuados (Virginia, 2018).

Aquellos ajustes permitieron llevar a cabo las negociaciones sobre el tema de una manera menos polarizada, dogmática y controversial en compara- 
ción al intento de resolución en El Caguán. O sea, el gobierno tuvo mayor autonomía y margen de maniobra, siendo capaz de aprovechar esta ventana de oportunidad para adoptar una postura más flexible respecto al problema de las drogas ilícitas. En este sentido, vale destacar la resolución adoptada en octubre de 2015 por la Corte Constitucional de detener la fumigación aérea de sembradíos de coca aduciendo impactos adversos del glifosato para la salud y el medioambiente (Otis,2015). Así, dio término a lo que había sido la piedra angular de la estrategia antinarcóticos implementada durante el Plan Colombia.

En respuesta a este viraje, las FARC se comprometieron a contribuir efectivamente con la solución definitiva al problema de las drogas ilícitas y, en un escenario de fin del conflicto, a revelar toda la información sobre su participación en la actividad ilícita y romper totalmente sus vínculos con el narcotráfico, modificándose así la relación entre farianos y campesinos como base del capital político de las FARC. El hecho que el gobierno haya convencido a los farianos de reconocer su participación y cooperar para desmantelar el narcotráfico no solo representó una garantía de enorme importancia para la sociedad colombiana y un paso concreto en su transición hacia la vida civil. También demostró que el narcotráfico era utilizado para mejorar su capacidad militar y proporcionar servicios sociales a las poblaciones bajo su control. O sea, el ex movimiento insurreccional nunca estuvo motivado por la avaricia para proseguir su lucha, pues no se criminalizó por completo, sino que adquirió un carácter híbrido a través del conflicto armado a consecuencia de su instrumentalización, transitando a una convergencia motivacional.

Inicialmente, los rebeldes negaron todas las afirmaciones que los vinculaban con esta economía ilícita, pero como la evidencia indicaba que las ganancias de la droga habían financiado su actuar desde hace décadas, este relato fue rechazado de plano por Santos. En este sentido, Timochenko insistió en que se vieron obligados a establecer un régimen de tributación y regulación a las transacciones realizadas por campesinos, siempre pensando en sus derechos, protegiéndolos frente a abusos de intermediarios y narcotraficantes, sin desatender nuestro propósito político mayor: la toma del poder (OACP, 2018:73).

Vale recordar que los altos mandos de la guerrilla percibían el narcotráfico como una enfermedad social y, consecuentemente con su tendencia político-ideológica, permanecieron firmemente comprometidos con hallar medios de subsistencia alternativos para los cultivadores de coca como parte de las negociaciones de paz en la capital cubana.

En efecto, la clave para zanjar este punto radicó en conciliar las convicciones de los farianos con su agenda criminal pues, en vez de atacar abierta- 
mente o bloquear el proceso de paz en La Habana, sus cabecillas lo subvirtieron para obtener concesiones que favorecieran sus objetivos políticos antes de renunciar a esta economía ilícita. Así, su participación en el narcotráfico llevó a que el acuerdo final de paz estableciera que la Jurisdicción Especial para la Paz evaluaría caso por caso si este delito se llevó a cabo para financiar la rebelión, o para obtener ganancias personales. Así, el narcotráfico sería catalogado un "delito político conexo" si se comprobase que fue utilizado para financiar su lucha insurgente, pudiendo ser amnistiado. Esta disposición intentaba abordar las preocupaciones de ex líderes de las FARC para evitar su extradición a Estados Unidos por tal delito y ser inhabilitados para ejercer cargos públicos (Crisis Group, 2018).

Resulta preciso, además, señalar que este nuevo abordaje del vínculo entre las FARC y el narcotráfico fue facilitado por el rol desempeñado por el gobierno estadounidense. Mientras que en El Caguán fue crítico, en La Habana fue marginal. Su capacidad para modelar el comportamiento de la administración Santos en relación a la "guerra contra las drogas" se vio mermada producto de los recortes presupuestarios sufridos tras la crisis $s u b$ prime (ver Gráfico 3).

\section{GRÁFICO 3}

Cooperación Estados Unidos-Colombia (1998-2016)

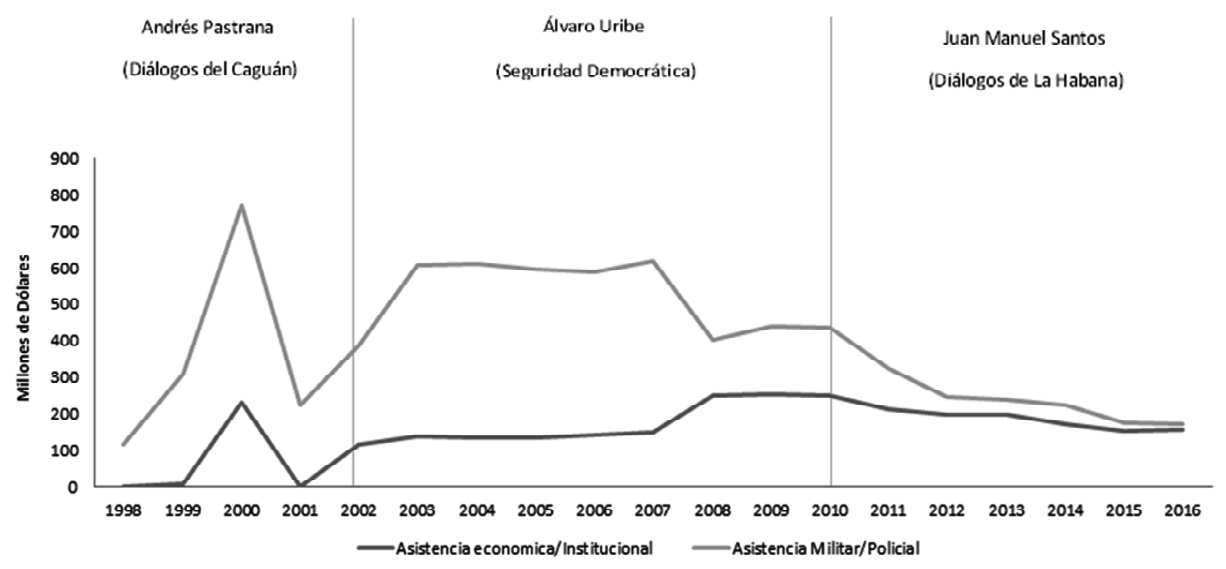

Fuente: Elaboración propia a partir de Isacson y Sánchez, 2017.

Igualmente, Colombia fue incapaz de mantener el interés de Washington en el conflicto y atraer su cooperación militar. Cabe recordar que la postura del expresidente Barack Obama sobre la "guerra contra el terrorismo" fue 
más mesurada y cautelosa respecto de su predecesor, George W. Bush (Borda, 2013). Probablemente esto desincentivó a Santos de enmarcar su lucha contra el ejército irregular en esta cruzada global, lo que obstaculizó el desembolso de mayores recursos económicos por parte de la Casa Blanca.

Bajo esa lógica, cabe resaltar que en febrero de 2015 Obama designó a Bernard Aronson como representante del gobierno e interlocutor en La Habana, con la venia de los protagonistas. Su rol consistió en comunicar los avances en las conversaciones. Acto seguido, el otrora Secretario de Estado, John Kerry, expresó públicamente el respaldo de Washington al esfuerzo de Santos por resolver el conflicto armado: "Creemos que este [proceso] ayudará a lograr una paz justa y duradera para todos los colombianos, y estamos dispuestos a apoyar la implementación del acuerdo" (Verdad Abierta, 2017).

En febrero de 2016, Obama, anticipándose a un posible acuerdo, diseñó un paquete de ayuda llamado Paz Colombia (cuya partida inicial contempló US $\$ 450$ millones) con el objetivo de consolidar y hacer sostenible la paz en el país andino, incluyendo ayuda exterior para reducir la producción de cultivos ilícitos, basado en la cooperación bilateral establecida durante el Plan Colombia (Beittel y Rosen, 2017). La Casa Blanca únicamente se involucró en las conversaciones a medida que los puntos acordados fueran de su particular interés, tales como la no extradición de farianos por narcotráfico en tanto delito político conexo. Por consiguiente, es posible señalar que el gobierno colombiano no asumió ningún costo político, ni en el plano doméstico ni internacional, por apartarse, al menos simbólicamente, de la "guerra contra las drogas".

Todos los factores expuestos previamente contribuyeron a que, durante las negociaciones de La Habana, el gobierno colombiano y las FARC acordaran una estrategia antinarcóticos conjunta basada en tres pilares, a saber:

- Cultivos ilícitos desde un enfoque de desarrollo rural: crear un Programa Nacional Integral de Sustitución de Cultivos Ilícitos de la mano de las comunidades afectadas por los cultivos y con las autoridades nacionales, departamentales y locales. El proyecto se desarrollará con la participación de las comunidades que jugarán un rol en el diseño, ejecución y seguimiento de su implementación, bajo una lógica de integración territorial e inclusión social. Asimismo, esta iniciativa buscará resolver el problema mediante la sustitución voluntaria. Solo en caso que los cultivadores no quieran participar o incumplan sus compromisos, la erradicación será forzada.

- La lucha contra el crimen organizado y el narcotráfico: crear una estrategia integral para desarticular y judicializar de manera 
focalizada las redes de narcotráfico en el territorio. Igualmente, acordaron fortalecer la lucha contra el lavado de activos en todos los sectores de la economía y establecer estrictos controles a la producción y tráfico de insumos para la producción de narcóticos.

- El consumo desde la salud pública: se abordará con un enfoque de derechos humanos y salud pública. Se articularán las instituciones estatales y se coordinará un proceso con las comunidades y familias para realizar acciones de rehabilitación e inserción del consumidor de drogas ilícitas (OACP, 2018).

Por último, cabe subrayar que los acuerdos logrados sobre el problema de drogas ilícitas se reflejaron en una dramática caída en la intensidad de la confrontación armada (ver Gráfico 1). Entre diciembre de 2012 y agosto de 2016, las FARC declararon un total de seis ceses al fuego unilaterales y redujeron sus acciones contra fuerzas gubernamentales en un $90 \%$ (ver Gráfico 2), siendo ésta una fuerte señal de su compromiso a cooperar en la "guerra contra el narcotráfico". Sin embargo, no todos estos gestos fueron correspondidos inmediatamente: la cúpula rebelde anunció un alto el fuego unilateral desde un comienzo, pero Santos fue desconfiado de sus movimientos a raíz de la experiencia en El Caguán. Por tal motivo, no cedió hasta que el tema se abordara formalmente en las negociaciones y las dudas sobre las intenciones de la guerrilla respecto a abandonar esta economía ilícita se disiparan. Finalmente, ambas partes acordaron apaciguar el conflicto. Así, el gobierno dejó de bombardear campamentos farianos en agosto de 2015 (alto el fuego de facto), mientras que los revolucionaros detuvieron todo enrolamiento y entrenamiento militar en octubre del mismo año.

\section{Actitudes}

Sin duda alguna, la interacción entre los farianos y el gobierno colombiano durante el proceso de paz llevado a cabo en el municipio caquetense estuvo marcada por una extrema desconfianza. Esto debido a que el comportamiento mostrado por la ex guerrilla respecto a la zona de distensión robusteció la percepción en Casa de Nariño que la codicia se había convertido en el principal impulso de aquella insurgencia: supuestamente mantenían la beligerancia para seguir obteniendo rentas ilícitas del narcotráfico.

Aquella visión es compartida por el gobierno estadounidense, quien optó por respaldar al gobierno colombiano para combatir a las FARC, provocando un punto de inflexión en la dinámica del conflicto armado y dando paso a su internacionalización. De este modo, las autoridades colombia- 
nas adoptaron una línea aún más dura contra el narcotráfico. En consecuencia, los rebeldes buscaron continuar beneficiándose del mercado, lo cual representó un formidable obstáculo para avanzar en las conversaciones con la ex guerrilla, permitiendo la continuidad de la guerra para suprimir su fuente ilícita de financiamiento.

El nexo de las FARC con el narcotráfico tuvo una incidencia negativa durante el proceso de paz en El Caguán al generar una guerra contra el narcotráfico, siguiendo la tipología propuesta por Jonsson et al (2016). Al respecto, cabe subrayar que las actitudes de ambos actores se tornaron más hostiles tras el colapso de las negociaciones. En efecto, la feroz ofensiva iniciada en 2002 por el ex mandatario Álvaro Uribe reafirmó la postura del gobierno colombiano de no hacer ninguna concesión ni comprometerse en otro cese al fuego basado en medidas de confianza. No obstante, las actitudes de ambos mutaron tras la llegada de Santos al poder.

En el caso de los diálogos de La Habana, sin embargo, el involucramiento fariano en el narcotráfico demostró no ser un obstáculo para llegar a una solución negociada, refutando la tesis de la feliz irresolubilidad de los conflictos armados planteada por Crocker et al (2005). Durante el último proceso de paz, ambas partes acordaron incluir el tema de las drogas ilícitas en la agenda de negociación. Esto envió una señal de que el gobierno colombiano estaba dispuesto a utilizar este momento potencialmente transformador para realizar ajustes en el enfoque tradicional en relación a la "guerra contra el narcotráfico”. Asimismo, Santos cambió la narrativa oficial respecto a las FARC pues, al menos públicamente, nunca se refirió a sus vínculos con el tráfico de drogas en comparación a Pastrana, quien se centró en aislar a los insurgentes.

Esta nueva actitud respecto de la participación del ejército revolucionario en este mercado ilícito se debió, principalmente, al hecho de que el gobierno estadounidense tuvo un rol marginal durante las conversaciones de paz de La Habana. Aunque Obama declaró su apoyo a los esfuerzos de paz del ex presidente colombiano, ningún funcionario de Washington participó directamente en las conversaciones y, en contraste con el proceso en El Caguán, la ayuda militar para la "guerra contra el narcotráfico" decayó, lo cual redundó en que su capacidad de presión sobre la Casa de Nariño se degradara. Las nuevas condiciones permitieron invitar públicamente a las FARC a comprometerse a solucionar el problema de las drogas ilícitas, generando así un cambio de actitud tendiente a cooperar con el cambio siguiendo la tipología de Jonsson et al (2016).

Fue así como su liderazgo manifestó la disposición a quebrar sus lazos con el narcotráfico, e incluso a apoyar los esfuerzos de las autoridades por combatirlo a cambio de concesiones durante la negociación, confirmando 
que no combatían por sus beneficios económicos. Este hecho permitió comprobar, también, que la beligerancia pudo finalizarse sin eliminar o, incluso, siquiera reducir substancialmente la mayor actividad criminal que financiaba a la guerrilla. De hecho, terminar la confrontación armada resultó ser una condición previa para suprimir la economía ilícita, y no a la inversa. Siendo posible concluir, entonces, que el nexo de las FARC con el narcotráfico tuvo una incidencia positiva durante el proceso de paz en Cuba.

\section{Análisis comparativo de ambos diálogos}

Como se puede observar en la tabla 1, el problema que las FARC y el Gobierno colombiano identificaron como lo central para configurar sus respectivas estrategias con miras a los diálogos del Caguán resultaron, más bien, antagónicos en cuanto al foco del mismo. En cambio, con los diálogos de La Habana, existe un importante punto de convergencia: la dinámica de la violencia. Ante esto, ambos actores coincidieron en la necesidad de solucionar el conflicto a través de la negociación.

Respecto del comportamiento, existe un importante foco de convergencia entre los actores: ambos coinciden en la extrema desconfianza hacia el otro. Ante esto, la estrategia que las FARC y el gobierno ocupan es también semejante, al utilizar ambos el periodo de negociación para replantear y expandir sus respectivas fuerzas y estrategias para el conflicto armado. De igual modo, existe una convergencia importante entre los actores referidos en la tabla 1: una visión revisionista de la negociación anterior y del proceso histórico que los llevó nuevamente a negociar. Esto amplió la perspectiva de ambos, al punto de entender que la coparticipación era indispensable para concluir el conflicto bajo una solución intermedia.

En el ámbito de las actitudes, la desconfianza extrema fue el patrón común entre las FARC y el gobierno durante los diálogos del Caguán, lo que llevó a la formación de percepciones distorsionadas acerca del móvil de cada actor respecto del otro para sostener el conflicto. Esto tiende a cambiar con los diálogos de La Habana. Si bien se repite la convergencia, esta vez en la voluntad de negociar sí existe un revisionismo histórico que allana la voluntad política para establecer un proceso de coparticipación, así como también amplía la perspectiva en cuanto a una desmovilización negociada, procurando evitar una nueva escalada de violencia que pusiera en peligro la existencia de las FARC y promoviendo su inclusión en el sistema político colombiano. Todo esto basado en la revisión de la política antinarcóticos del Gobierno y del vínculo entre insurgencia y narcotráfico de parte de las FARC. 


\section{Esteban Arratia, Diego Jiménez y Aldo Barria}

\section{TABLA 1}

Comparación de las posiciones del Gobierno y las FARC ante los diálogos

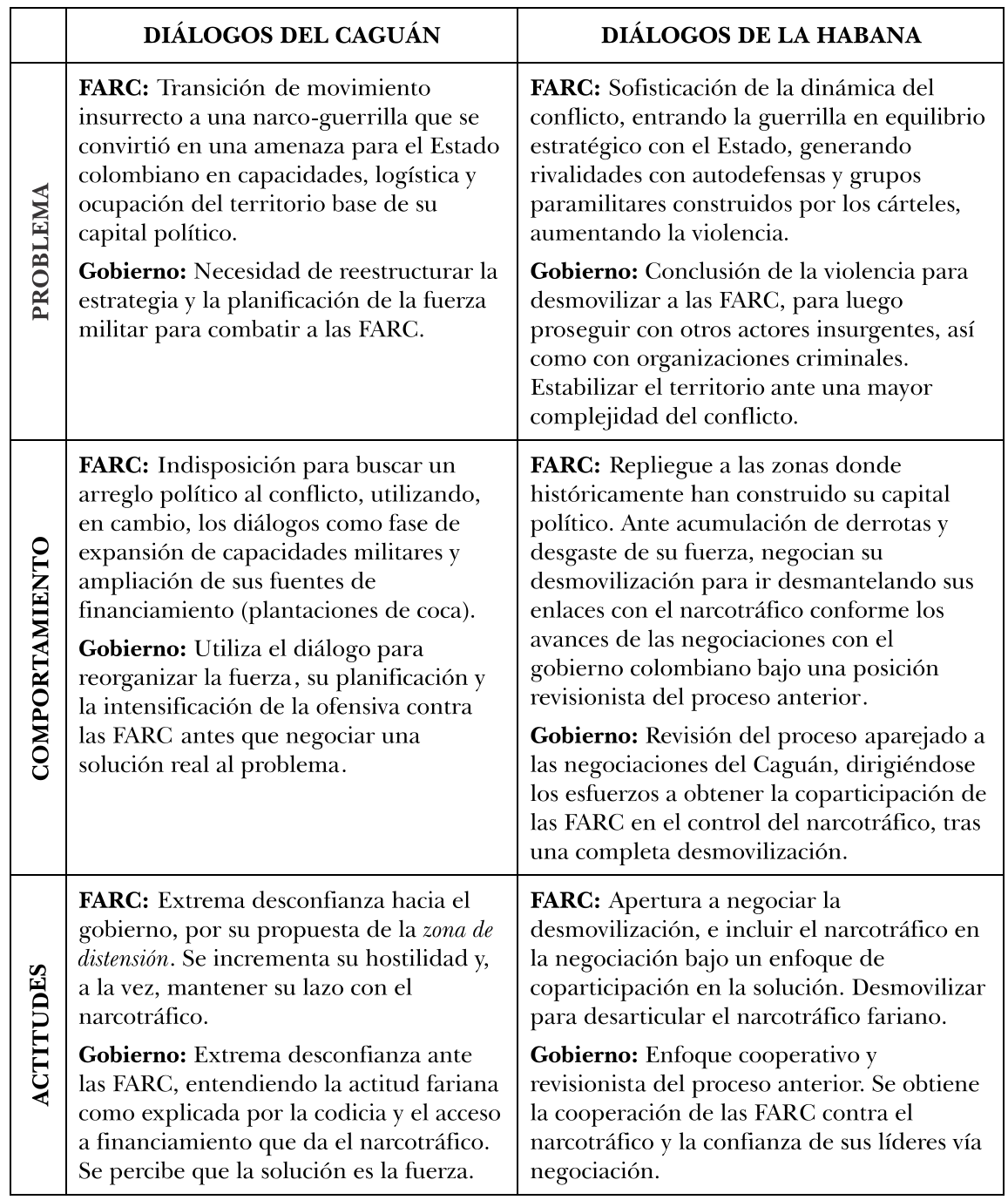

Fuente: Elaboración propia.

\section{Conclusiones}

Durante el proceso de paz del Caguán el tema fue abordado de una manera dogmática y controversial debido a la percepción de que la relación 
entre los farianos y el tráfico de drogas había adquirido un carácter simbiótico: supuestamente mantenían la beligerancia en ebullición para obtener rentas ilícitas asociadas al narcotráfico. Visión compartida por la Casa Blanca, que optó por involucrarse más activamente en el conflicto armado, respaldando al gobierno colombiano en sus esfuerzos por fortalecer el aparato militar y combatir a las FARC mediante el Plan Colombia, tornando su rol decisivo en la dinámica de la confrontación. Fue así como Pastrana adoptó una línea aún más dura contra el narcotráfico, representando un obstáculo para avanzar en las conversaciones con la ex guerrilla y dando pie a la continuación del enfrentamiento para suprimir su fuente ilícita de financiamiento. En consecuencia, el nexo de las FARC con el narcotráfico tuvo una incidencia negativa durante el proceso de paz en el municipio caquetense al generar una "guerra contra el narcotráfico".

En La Habana, el involucramiento fariano en el narcotráfico demostró no ser un obstáculo para llegar a una solución negociada básicamente por dos razones: Primero, el ex presidente Santos adoptó un discurso más revisionista sobre la estrategia antinarcóticos de ese entonces y, segundo, optó por modificar lenta pero decididamente la retórica oficial sobre el nexo entre las FARC y el tráfico de estupefacientes, cambios facilitados por el hecho que Washington tuvo un rol marginal durante las negociaciones. En respuesta a este viraje, las FARC se comprometieron a solucionar el problema de las drogas ilícitas, generando un cambio de actitud tendiente a cooperar con el cambio. Así, sus líderes manifestaron estar dispuestos a quebrar sus lazos con el narcotráfico e incluso apoyar los esfuerzos de las autoridades por combatirlo a cambio de concesiones, confirmando que no combatían por sus beneficios económicos. Por ende, el nexo de las FARC con el narcotráfico tuvo una incidencia positiva durante el proceso de paz en Cuba.

En este sentido, se puede afirmar que la divergencia producida entre el Gobierno y las FARC durante los diálogos del Caguán tendió a generar una convergencia. En efecto, mientras en dicho diálogo el diagnóstico del problema era prácticamente antagónico, existió una fuerte convergencia en este ámbito durante los diálogos de La Habana.

Lo anterior lleva también a que el comportamiento se acoplara con el problema definido, así como con las expectativas sobre el resultado de las negociaciones por parte de ambos actores. En este ámbito, el cambio resulta ser sustancial. Desde una negociación en donde la buena fe estuvo completamente ausente (diálogos del Caguán), se transita a un comportamiento altamente colaborativo, basado en una actitud revisionista de las fases pasadas del proceso, y con apertura a nuevas posibilidades de coparticipación (diálogos de La Habana). Una vez más, la negociación con enfoque pragmático desmantela la desconfianza para alcanzar una solución transaccional. 


\section{Referencias bibliográficas}

AKUF (13 de noviembre de 2018). Kolumbien. Universität Hamburg. Recuperado de https:/www.wiso.uni-hamburg.de/fachbereich-sowi/professuren/jakobeit/forschung/ akuf/kriegearchiv/lateinamerika/kolumbien.htm

Arjona, A. (2016). Rebelocracy: Social Order in the Colombian Civil War. Cambridge: Cambridge University Press.

Beittel, J. y Rosen, L. (2017). Colombia's Changing Approach to Drug Policy. Washington, DC: Congressional Research Service.

Bitar, S. y González, D. (2018). Colombia y Trump, entre la amistad y las drogas. Foreign Affairs Latinoamérica, 18(1), 25-32

Boer, J. y Bosetti, L. (2017). The Crime-Conflict Nexus Assessing the Threat and Developing Solutions. New York: United Nations University Centre for Policy Research.

Boer, J.; Garzón, J. y Bosetti, L. (2017). Criminal Agendas and Peace Negotiations The Case of Colombia. New York: United Nations University Centre for Policy Research.

Boer, J. y Bosetti, L. (2015). The Crime-Conflict "Nexus": State of the Evidence. New York: United Nations University Centre for Policy Research.

Borda, S. (2013). The search for a negotiated peace in Colombia and the fight against illegal drugs. Oslo: Norwegian Peacebuilding Resource Centre (NOREF).

Briscoe, I. (6 de noviembre de 2017). Colombia's coca boom: Behind the failure to erradicate crop. Foreign Affairs. Recuperado de: https:/www.foreignaffairs.com/ articles/colombia/2017-11-06/colombias-coca-boom

CERAC (30 de junio de 2017). Un conflicto largo, de terminación negociada. Monitor del cese el fuego bilateral y hostilidades. Recuperado de http://blog.cerac.org.co/ monitor-del-cese-el-fuego-bilateral-y-de-hostilidades-final

Crisis Group (2018). Risky Business: The Duque Government's Approach to Peace in Colombia. Bogota: Crisis Group Latin America.

Crisis Group (2014). The day after tomorrow: Colombia's FARC and the end of the conflict. Bogota: Crisis Group Latin America.

Crisis Group (2012). Colombia: Peace at Last? Bogota: Crisis Group Latin America.

Cockayne, J., Boer, J. y Bosetti, L. (2017). Going Straight Criminal Spoilers, Gang Truces and Negotiated Transitions to Lawful Order. New York: United Nations University Centre for Policy Research.

Crocker, C., Osler, F. y Aal, P. (2005). Grasping the Nettle: Analyzing Cases of Intractable Conflict. Washington, DC: USIP Press.

Collier, P. (2006). Economic Causes of Civil Conflict and Their Implications for Policy. Oxford: Oxford University.

Collier, D. (2011). Understanding Process Tracing. En Political Science and Politics, 44(4), 823-830.

Comolli, V. (24 de mayo de 2018). Illicit trafficking and conflict: a chicken-and-egg situation? International Institute for Strategic Studies. Recuperado de https:// www.iiss.org/blogs/analysis/2018/05/illicit-trafficking-and-conflict. 
Cornell, S. (2007). Narcotics and Armed Conflict: Interaction and Implications. Studies in Conflict E Terrorism, 30(3), 207-227.

Diehl, P. (2016). Exploring Peace: Looking Beyond War and Negative Peace. International Studies Quarterly, 60, 1-10.

Dudouet, V. y Galvanek, J. (2018). Financing armed groups during ceasefires. Oslo: Norwegian Centre for Conflict Resolution (NOREF).

Echandía, C. (2011). Situación actual de las FARC: un análisis en los cambios de las estrategias y territorialidad (1990-2011). Bogotá: Fundación Ideas para la Paz.

Felbab-Brown, V.; Trinkunas, H. y Hamid, S. (2018). Militants, Criminals, and Warlords: The Challenge of Local Governance in an Age of Disorder. Washington, DC: Brookings Institution Press.

Felbab-Brown, V. (2010). Shooting up Counterinsurgency and the War on Drugs. Washington, DC: Brookings Institution Press.

Felter, C. y Renwick, D. (11 de enero de 2017). Colombia's Civil Conflict. Council on Foreign Relations. Recuperado de https://www.cfr.org/backgrounder/colombias-civil-conflict

FIP (2017). Violencia Homicida en Colombia. Instinto de Vida. Recuperado de http:/ /www.ideaspaz.org/especiales/data-fip/homicidios/gra.html

Fisas, V. (2017). Anuario de procesos de paz 2016. Barcelona: Escola de Cultura de Pau. Galtung, J. (1996). Peace by Peaceful Means: Peace and Conflict, Development and civilization. Oslo: Sage Publications.

Garzón, J. (2015). Avoiding the Perfect Storm: Criminal Economies, Spoilers, and the Post-Conflict Phase in Colombia. Stability: International Journal of Security E Development, 4(1), 1-15

Gerring, J. (2007). Case study research: Principles and practices. New York: Cambridge University Press.

GIATOC (2018). Organized crime and its role in contemporary conflict: An analysis of UN Security Council Resolutions. Geneva: Global Initiative Against Transnational Organized Crime.

Harto, F. (2016). La construcción del concepto de paz: paz negativa, paz positiva y paz imperfecta En Cuadernos de Estrategia (pp.119-146). Madrid: Instituto Español de Estudios Estratégicos.

Höglund, K. y Söderberg, M. (2010). Beyond the absence of war: the diversity of peace in post-settlement societies. Review of International studies, 36(2), 367-390.

Isacson, A. y Sánchez, G. (15 de mayo de 2017). President Trump and Colombia's Santos to Meet this Week. En WOLA. Recuperado de https:/www.wola.org/analysis/ president-trump-colombias-santos-meet-week/

Isacson, A. (4 de febrero de 2016). The Many Lessons of Plan Colombia. WOLA. Recuperado de https:/www.wola.org/analysis/the-many-lessons-of-plan-colombia/ Jonsson, M., Brennan, E. y O’ Hara, C. (2016). Financing War or Facilitating Peace? The Impact of Rebel Drug Trafficking on Peace Negotiations in Colombia and Myanmar. Studies in Conflict E Terrorism, 39(6), 542-559. 
Keen, D. (1998). The Economic Functions of Violence in Civil Wars. London: International Institute for Strategic Studies.

Makarenko, T. (2008). Criminal and Terrorist Networks: Gauging Interaction and the Resultant Impact on Counter-Terrorism. En Brimmer, E. (Ed). Five Dimensions of Homeland and International Security (pp.58-72). Washington, DC: Johns Hopkins University

McDermott, J. (6 de septiembre de 2017). The FARC's riches: Up to $\$ 580$ million in annual income. En InSight Crime - Investigation and analysis of organized crime. Recuperado de https:/www.insightcrime.org/news/analysis/farc-riches-yearlyincome-up-to-580-million/

McQuinn, B. (2016). DDR and the Internal Organization of Non-State Armed Groups. Stability: International Journal of Security and Development, 5(1), 1-24

Muñoz, F. (2010). Pax Orbis. Complejidad y conflictividad de la paz. Granada: Editorial Universidad de Granada.

OACP (2018). La discusión del punto 4: Solución al problema de las Drogas Ilícitas. Bogotá: Oficina del Alto Comisionado para la Paz (OACP).

Otis, J (15 de mayo de 2015).Colombia will end coca crop-dusting, citing health concerns. NPR. Recuperado de http://www.npr.org/sections/parallels/2015/05/15/ 406988063/colombia-will-end-coca-crop-dusting-citing-health-concerns.

Pécault, D. (2008). Las FARC: Fuentes de su longevidad y la conservación de su cohesión. Análisis Político, (63), 22-50.

Phillips, B (2015). How Does Leadership Decapitation Aect Violence? The Case of Drug Tracking Organizations in Mexico. The Journal of Politics, 77(2), 324-336.

Ríos, J. (2016). La narcotización del activismo guerrillero de las FARC y el ELN, 1998-2012. UNISCI Journal, 41, 205-233.

Ross, M. (2004). What do we know about Natural Resources and Civil War? Journal of Peace Research, 41(3), 337-356.

Sartori, G. (2011). Cómo hacer ciencia política. Lógica, método y lenguaje en las ciencias sociales. Madrid: Editorial Taurus.

Shaw, M. y Mahadevan, P. (2018). When terrorism and organized crime meet. Zurich: Center for Security Studies.

Shaw, M., Nellemann, C. y Stock, J. (2018). World atlas of illicit flows. Geneva: Global Initiative Against Transnational Organized Crime.

Stedman, S. (1997). Spoiler problems in peace processes. International Security, 22(2), 5-53.

Tickner, A. (18 de marzo de 2014). Colombia, the United States, and Security Cooperation by Proxy. WOLA. Recuperado de https://www.wola.org/analysis/ colombia-the-united-states-and-security-cooperation-by-proxy/.

UCDP (2018). Government of Colombia-FARC. Uppsala Conflict Data Program. Recuperado de http://ucdp.uu.se/\#/statebased/623

UNODC (2018). World Drug Report 2017. Viena: United Nations Office on Drugs and Crime. 
Verdad Abierta (16 de enero de 2017). En la era de Trump, ¿̇habrá respaldo al acuerdo de paz? Procesos de paz. Recuperado de https:/verdadabierta.com/en-la-erade-trump-habra-respaldo-al-acuerdo-de-paz/

Villalobos, J. (2011). De Los Zetas al Cartel de La Habana. Foreign Affairs Latinoamérica, $11(2), 10-21$

Virginia, S. (2018). Narcotization as Security Dilemma: The FARC and Drug Trade in Colombia. Studies in Conflict Ẽ Terrorism, 41(8), 638-659.

Wallensteen, P. y Joshi, M. (2018). Understanding Quality Peace: Peacebuilding after Civil War. New York: Routledge.

\title{
Palabras Clave
}

Conflicto armado - Fuerzas Armadas Revolucionarias de Colombia (FARC) Narcotráfico - Procesos de Paz.

\section{Keywords}

Armed conflict — Drug trafficking - Revolutionary Armed Forces of Colombia (FARC) - Peace processes.

\begin{abstract}
How affects participation of insurgent groups in drug trafficking on peace processes? This article answers the question using two study cases: "Caguan's Negotiations" (1998-2002) and "Havana's Negotiations" (2012-2016). In August 2016, former President Santos signed an historic peace deal with the Revolutionary Armed Forces of Colombia (FARC), ending 52 years of conflict. In this way, the profits of drug trafficking, as source of financing, impeded a negotiated solution with Pastrana's government, becoming a critical issue during the talks that had taken place in Cuba. Therefore, this article compares negotiations of Caguán (1998-2002) and Havana (20122016), in order to help the Peace Triangle as analytical tool, seeking to show the changes in behavior and attitudes of its protagonists as a link between FARC and drug trafficking.
\end{abstract}

